\title{
THE HARVESTING OF HIGH LIPID CONTENT MICROALGAE BIOMASS THROUGH A FLOCCULATION STRATEGY
}

\author{
J. S. Lemos ${ }^{\mathrm{a}}$, \\ J. V. C. Vargas ${ }^{a}$, \\ A. B. Mariano ${ }^{a}$, \\ V. M. Kava ${ }^{a}$, \\ J. C. Ordonez ${ }^{\mathrm{b}}$, \\ and J. O. Klein $\mathbf{J r}^{\mathrm{a}}$ \\ ABSTRACT \\ Different flocculants were evaluated for the flocculation of microalgae \\ biomass of Acutodesmus obliquus. Flocculation was tested with $\mathrm{FeCl}_{3}$ and \\ $\mathrm{NaOH}$ at different concentrations and compared to a sample centrifuged at \\ $7000 \mathrm{rpm}$. The evaluated parameters were absorbance $(540 \mathrm{~nm})$ in the \\ clarified medium, and lipids concentration. For $\mathrm{FeCl}_{3}\left(0.2 \mathrm{mmol} \mathrm{L}{ }^{-1}\right)$ as \\ flocculant, efficiency was $96.8 \%$, and with $\mathrm{NaOH}\left(8 \mathrm{mmol} \mathrm{L}^{-1}\right) 93.5 \%$. \\ Centrifugation efficiency was lower than with either flocculants: $91.7 \%$. \\ However, $\mathrm{NaOH}$ flocculation reduced lipid content, which did not occur \\ with $\mathrm{FeCl}_{3}$. Flocculation efficiency was affected by salt concentration, \\ ${ }^{a}$ Universidade Federal do Paraná \\ Programa de Pós-Graduação em Engenharia e \\ reducing efficiency by $79 \%$ due to increased nutrient concentration $(9 \mathrm{~mL}$ \\ $\left.\mathrm{L}^{-1}\right)$. \\ Ciência dos Materiais (PIPE) \\ Núcleo de Pesquisa e Desenvolvimento em \\ Energia Auto-Sustentável (NPDEAS) \\ Bairro Jardim das Américas \\ CEP 81531-980 \\ Curitiba, Paraná, Brasil \\ jvargas@demec.ufpr.br \\ ${ }^{b}$ Department of Mechanical Engineering, \\ Energy and Sustainability Center, and Center \\ for Advanced Power Systems \\ Florida State University \\ Tallahassee, FL 32310 USA \\ ordonez@caps.fsu.edu \\ Received: September 18, 2018 \\ Revised: October 19, 2018 \\ Accepted: November 12, 2018 \\ Keywords: biodiesel; microalgae; flocculation; lipids; Acutodesmus \\ obliquus
}

\section{NOMENCLATURE}

$\mathrm{A}_{1}$

absorbance of the clarified medium after flocculation

$\mathrm{A}_{2} \quad$ absorbance of the cultivation medium before flocculation

C molar concentration, $\mathrm{mmol} \mathrm{L}^{-1}$

$\mathrm{S} \quad$ standard deviation

$\mathrm{Z} \quad$ error propagation

\section{Greek symbols}

$\alpha \quad$ absorbance

$\eta \quad$ efficiency of biomass recovery

$\lambda$ lipid content

\section{INTRODUCTION}

The number of studies seeking the replacement of fossil fuels for biodiesel has increased due to the technical advantages biodiesel has over diesel, such as lower flash point, reduction of sulfur and carbon monoxide in the emissions, absence of aromatic hydrocarbons and other chemicals harmful to health and the environment, renewability, biodegradability, sustainability of the production process, etc (Beltrão and Oliveira, 2010; Huang et al., 2010). When vegetable oil is used in the biodiesel production process, the cost of raw material corresponds to approximately $70-85 \%$ of the total production cost (Meng et al., 2009). The use of grains for the production of biodiesel tends to increase the cost of the raw material, because of the competition with the food industry. However, higher plants oil could be replaced by microalgae oil (Mallick et al., 2012).

The main advantage of using microalgae as raw material for biodiesel production consists of the uniformity of the organism, differently from plants that have leaves, stems, fruits, seeds and roots that must be separated before the extraction of fatty acids. In addition to that, other microalgae positive aspects in comparison to crops could be cited: lower 
investment cost for cultivation; usage of land unsuitable for agriculture; lower demand for land, higher amount of stored lipids compared to plant oilseeds; and possibility to capture carbon dioxide from a pollutant source. Likewise, other valuable products, such as biogas, could be obtained from the residual biomass after lipid extraction (Hundt and Reddy, 2011; Chisti et al., 2007).

Biomass separation from the culture medium is challenging due to the low concentration of microalgae in the medium, the cell having about the same density as that of water and the small cell diameter (3-30 $\mu \mathrm{m})$. Therefore, it may represent a laborious, long and expensive step in the biodiesel production process from microalgae, according to the desired efficiency and volume involved. The separation cost may represent $20-30 \%$ of total biomass production cost (González-Fernández et al., 2012; Grima et al., 2003; Lourenço, 2006; Uduman et al., 2010).

Biomass separation may be achieved through centrifugation, filtration or sedimentation. Centrifugation may not be feasible to processes with high volumes of medium when the final products have low added value, due to the high energy cost (Lee et al., 2009; Pienkos et al., 2009; Schlesinger, 2012). In a large scale system, vacuum or pressure filters are satisfactory to recover microalgae biomass containing large or filamentous cells such as Coelastrum proboscideum and Spirulina platensis, but fail to recover small cells from Acutodesmus, Scenedesmus, Dunaliella and Chlorella genera, for example, which rapidly obstruct the membrane (Grima et al., 2003). Microalgae sedimentation is slow and, consequently, with reduced efficiency. Rapid sedimentation may occur during microalgae cultivation due to the grouping of cell colonies and changes in the medium characteristics allowing selfflocculation, however, the occurrence of these factors is unpredictable, thus, it is not possible to rely on them to increase the sedimentation rate in a process of biomass recovery. The rate of sedimentation, as well as filtration and centrifugation, may be increased by flocculation, which increases the effective size of the particles (Grima et al., 2003). Flocculation is an economically viable process, however, depending on the chemical characteristics of the flocculant agent, it may cause the rupture of the cells and, consequently, the loss of the metabolic product of interest (Lee et al., 2009). Also, the biomass recovery efficiency with flocculation may vary even when the same conditions are used.

Based on the state-of-the-art on the subject, it is reasonable to state that effective alternative flocculation strategies are still needed. Therefore, this study aimed to experimentally establish a flocculation process for the recovery of microalgae biomass of Acutodesmus obliquus with efficiency similar to centrifugation and without loss of intracellular lipids. The relationship between salt concentration in the cultivation medium and the flocculation efficiency was also investigated.

\section{MATERIALS AND METHODS}

The experiments were performed with microalgae Acutodesmus obliquus, courtesy of the Integrated Group of Aquaculture of the Federal University of Paraná (GIA - UFPR). The microalgae was cultivated in Guillard " $\mathrm{f} / 2$ " modified medium (Lourenço, 2006) in 2 L Erlenmeyer flasks, with aeration rate of $0.05 \mathrm{~L} . \mathrm{s}^{-1}$ of atmospheric air per liter of culture and without photoperiod. Two incubation conditions were used in order to have samples with different biomass concentrations: in condition $\mathrm{A}$, microalgae was cultivated at $17 \pm 0.2^{\circ} \mathrm{C}$ for nine days resulting in final biomass concentration of $0.28 \pm$ $0.002 \mathrm{~g} \mathrm{~L} \mathrm{~L}^{-1}$, and in condition $\mathrm{B}$, microalgae was cultivated at $22 \pm 2^{\circ} \mathrm{C}$ for four days, achieving $0.12 \pm$ $0.002 \mathrm{~g} \mathrm{~L}^{-1}$ of biomass.

\section{Microorganism and Cultivation Conditions}

The experiments were performed with microalgae Acutodesmus obliquus, courtesy of the Integrated Group of Aquaculture of the Federal University of Paraná (GIA - UFPR). The microalgae was cultivated in Guillard " $\mathrm{f} / 2$ " modified medium (Lourenço, 2006) in 2 L Erlenmeyer flasks, with aeration rate of $0.05 \mathrm{~L} . \mathrm{s}^{-1}$ of atmospheric air per liter of culture and without photoperiod. Two incubation conditions were used in order to have samples with different biomass concentrations: in condition $\mathrm{A}$, microalgae was cultivated at $17 \pm 0.2{ }^{\circ} \mathrm{C}$ for nine days resulting in final biomass concentration of 0.28 $\pm 0.002 \mathrm{~g} \mathrm{~L}^{-1}$, and in condition $\mathrm{B}$, microalgae was cultivated at $22 \pm 2^{\circ} \mathrm{C}$ for four days, achieving $0.12 \pm$ $0.002 \mathrm{~g} \mathrm{~L}^{-1}$ of biomass.

\section{Flocculation Tests}

The flocculation tests were performed with different flocculants, ferric chloride $\left(\mathrm{FeCl}_{3} \cdot 6 \mathrm{H}_{2} \mathrm{O}\right)$ and sodium hydroxide $(\mathrm{NaOH})$. For both flocculants, the same agitation conditions were used: rapid stirring of $500 \mathrm{rpm}$ for 5 seconds, slow agitation of $250 \mathrm{rpm}$ for $5 \mathrm{~min}$ and settling for $10 \mathrm{~min}$. The absorbance $(\alpha)$ of the samples was measured before and after flocculation. Absorbances were measured using a Shimadzu UV -1800 spectrophotometer, with operating wavelength ranging from 190 to $1100 \mathrm{~nm}$ with $1 \mathrm{~nm}$ resolution. The measurements were taken for a wavelength of $540.0 \mathrm{~nm}$ using a $1 \mathrm{~cm}$ spectrophotometer cuvette. The efficiency of biomass recovery $(\eta)$ was determined as follows:

$$
\eta(\%)=\left(1-\frac{\mathrm{A}_{1}}{\mathrm{~A}_{2}}\right) \times 100
$$


where $A_{1}$ is the absorbance of the clarified medium after flocculation and $\mathrm{A}_{2}$ is the absorbance of the cultivation medium before flocculation. For comparison, a sample of the medium culture was centrifuged for $15 \mathrm{~min}$ at $7000 \mathrm{rpm}$ and at $4{ }^{\circ} \mathrm{C}$ and the resulting efficiency was compared to the efficiencies of the flocculation tests (Soares, 2010). The optimum concentration (C) for each flocculant was selected based on biomass recovery efficiencies measured when flocculating samples obtained in cultivation condition $\mathrm{A}$.

\section{Flocculation Mechanism}

The flocculation mechanism was investigating using samples obtained in cultivation condition $\mathrm{B}$, in which biomass concentration is lower than in samples obtained in condition A. The samples were flocculated using $\mathrm{NaOH}$ and $\mathrm{FeCl}_{3}$ at their optimum concentration of flocculant (previously determined for samples in condition A) and at five times their optimum.

\section{Effect of Salt Concentration in the Cultivation Medium on Flocculation Efficiency}

In order to verify the influence of salt concentration in the medium on the efficiency of flocculation, three samples containing different salt concentrations were flocculated with the same concentration of $\mathrm{FeCl}_{3}$. The following samples were used:

- Sample 1: obtained in cultivation condition B;

- Sample 2: obtained in cultivation condition B, added $5 \mathrm{~mL} \mathrm{~L}{ }^{-1}$ of the nutrients solutions of the modified Guillard " $\mathrm{f} / 2$ " medium in sample after cultivation but before flocculation, and

- Sample 3: obtained in cultivation condition B, added $9 \mathrm{~mL} \mathrm{~L}^{-1}$ of the nutrients solutions of the modified Guillard " $\mathrm{f} / 2$ " medium in sample after cultivation but before flocculation.

\section{Analysis of Lipid Content}

The lipid content (or mass fraction, w/w), $\lambda(\%)$, was analyzed in the recovered biomass of the centrifugation and the flocculation processes with the optimum concentration of each flocculant, using the adapted Bligh \& Dyer method (Rodríguez et al., 2007).

\section{Statistical Analysis}

All measurements results are expressed as mean values $\pm 2 \mathrm{~S}$ (standard deviation), while the calculated values are expressed as mean values $\pm \mathrm{Z}$ (error propagation). Statistical differences between experimental groups were assessed by analysis of variance (Student's t-test), with a significance level of $95 \%$.

\section{RESULTS}

\section{Efficiency of Flocculation}

In order to identify an efficient process of flocculation for A. obliquus, the microalgae were cultivated for nine days (condition A) and samples of the homogeneous culture were used to conduct tests using centrifugation and flocculation with $\mathrm{FeCl}_{3}$ and $\mathrm{NaOH}$ at different concentrations. After flocculation, the absorbance value and $\mathrm{pH}$ of the clarified medium were determined, for $\mathrm{NaOH}$ and $\mathrm{FeCl}_{3}$, as shown in Figs. 1 and 2, respectively.

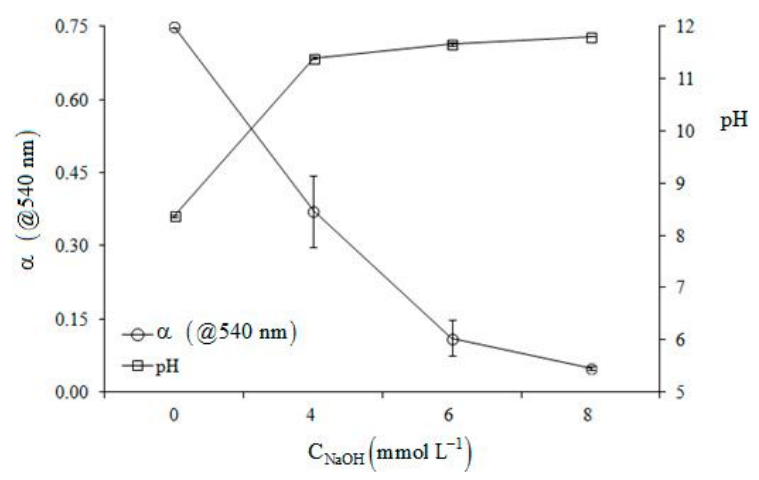

Figure 1. The $\mathrm{pH}$ and absorbance of clarified medium variation after flocculation of sample 1 with respect to $\mathrm{NaOH}$ concentration.



Figure 2. The $\mathrm{pH}$ and absorbance of clarified medium variation after flocculation of sample 1 with respect to $\mathrm{FeCl}_{3}$ concentration.

The samples with $\mathrm{NaOH}$ concentration of 8 mmol $\mathrm{L}^{-1}$ showed a significantly higher recovery when compared to the sample with 4 and $6 \mathrm{mmol} \mathrm{L}^{-1}$. In order to obtain a high biomass removal from the cultivation medium, the $\mathrm{pH}$ of the samples varied from 8.38 to 11.81 . When using ferric chloride, the highest cell recovery was obtained in the samples with $\mathrm{C}_{\mathrm{FeCl}_{3}}=0.2 \mathrm{mmol} \mathrm{L}^{-1}$, while the sample with $0.3 \mathrm{mmol} \mathrm{L}^{-1}$ a similar value for absorbance, indicating loss of ability to recover biomass or excess of iron in solution. In the flocculation tests with ferric chloride the $\mathrm{pH}$ of the clarified medium was reduced from 8.38 to 6.87 , for $0.2 \mathrm{mmol} \mathrm{L}^{-1}$, because the 
solubilization of $\mathrm{FeCl}_{3}$ in the sample formed hydrochloric acid.

Table 1 shows the biomass recovery efficiency $(\eta)$ for the flocculation tests and for centrifugation, calculated with Eq. (1). The recovery efficiencies at $\mathrm{C}_{\mathrm{NaOH}}=8 \mathrm{mmol} \mathrm{L}^{-1}$ and $\mathrm{C}_{\mathrm{FeCl}_{3}}=0.2 \mathrm{mmol} \mathrm{L}^{-1}$, highlighted in Tab. 1, were higher than the efficiency with centrifugation.

Table 1. Efficiency of biomass recovery with centrifugation and flocculation at different concentrations of $\mathrm{NaOH}$ and $\mathrm{FeCl}_{3}$.

\begin{tabular}{|c|c|c|}
\hline \multirow{2}{*}{ Process } & \multicolumn{2}{|c|}{ Biomass Recovery Efficiency } \\
\cline { 2 - 3 } & $\begin{array}{c}\text { Flocculant concentration, } \\
\text { C (mmol L-1) }\end{array}$ & Efficiency, $\boldsymbol{\eta}$ \\
\hline Centrifugation & - & $91.7 \%$ \\
\hline Flocculation & 4 & $50.6 \%$ \\
with $\mathrm{NaOH}$ & 6 & $85.3 \%$ \\
& 8 & $93.5 \%$ \\
\hline Flocculation & 0.1 & $82.8 \%$ \\
with $\mathrm{FeCl}_{3}$ & 0.2 & $96.8 \%$ \\
& 0.3 & $96.6 \%$ \\
\hline
\end{tabular}

\section{Flocculation Mechanism}

For samples obtained in cultivation conditions $B$, which resulted in approximately half of the biomass concentration from condition $\mathrm{A}$, the amount of flocculant necessary for maximum biomass recovery would be $\mathrm{C}_{\mathrm{NaOH}}=4 \mathrm{mmol} \mathrm{L}^{-1}$ and $\mathrm{C}_{\mathrm{FeCl}_{3}}=0.1 \mathrm{mmol} \mathrm{L}^{-1}$, based on the stoichiometric relation between cell concentration in the medium and the amount of flocculant necessary to remove it (Wyatt et al., 2012; Chen et al., 2013) and the optimum flocculant concentration determined for samples from condition A. However, the samples from condition B were flocculated with flocculant in excess, 2 and 12 times the concentration necessary, in order to identify the flocculation mechanism of $\mathrm{NaOH}$ and $\mathrm{FeCl}_{3}$. The efficiency of cell recovery for flocculation with $\mathrm{NaOH}$ increased with the concentration of the flocculant in the sample, as shown in Fig. 3, unlike in the flocculation with $\mathrm{FeCl}_{3}$, as shown in Fig. 4, in which the ability to recover the biomass decreases with a higher flocculant concentration.

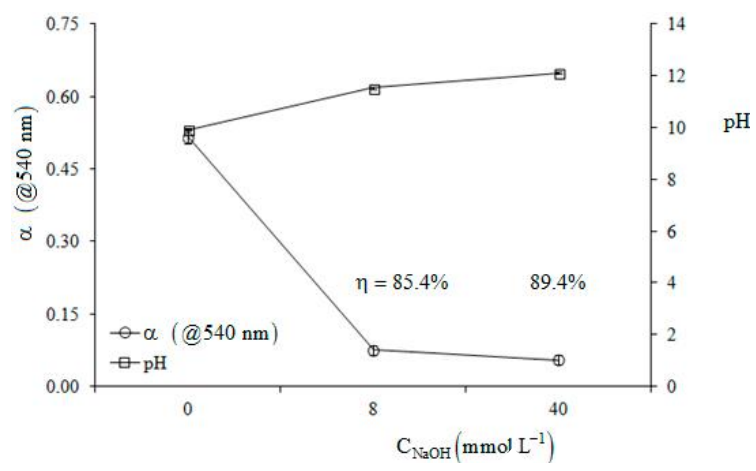

Figure 3. The $\mathrm{pH}$ and absorbance of clarified medium variation after flocculation of sample 2 with respect to $\mathrm{NaOH}$ concentration. Biomass recovery efficiencies are also shown in selected points.

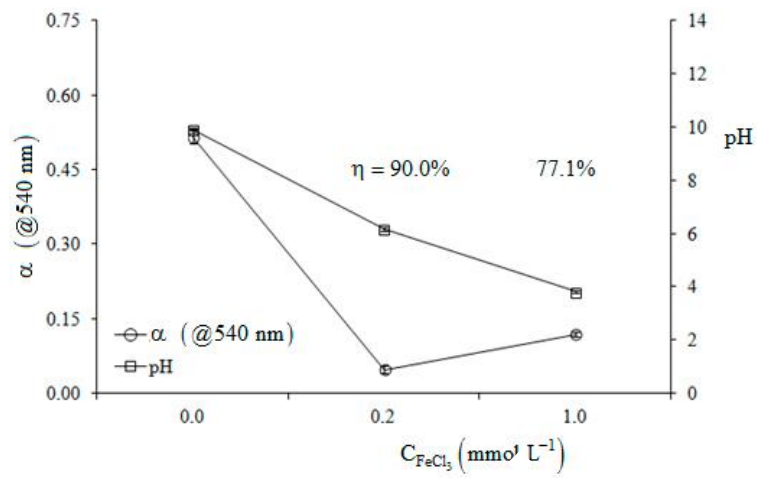

Figure 4. The $\mathrm{pH}$ and absorbance of clarified medium variation after flocculation of sample 2 with respect to $\mathrm{FeCl}_{3}$ concentration. Biomass recovery efficiencies are also shown in selected points.

When comparing flocculation of condition A and $\mathrm{B}$ with the same amount of flocculant, $\mathrm{C}_{\mathrm{NaOH}}=8 \mathrm{mmol} \mathrm{L}^{-1}$ and $\mathrm{C}_{\mathrm{FeCl}_{3}}=0.2 \mathrm{mmol} \mathrm{L}^{-1}$, there was a reduction in efficiency from condition $\mathrm{A}$ to $\mathrm{B}$ for both flocculants (labels of Figs. 3 and 4), although biomass concentration is lower in condition B. This behavior cannot be attributed only to flocculant overdose, because efficiency is increased with overdose when $\mathrm{NaOH}$ is used as flocculant, as shown in Fig. 3. The reduction in efficiency from condition A to B may be caused by the higher concentration of salts present in sample $B$, since the cultivation time was lower, thus, microalgae consumed less nutrients that in condition A.

The flocculation process of colloidal substances in suspension due to the addition of electrolyte salts in solution can occur by three mechanisms: double-layer compression, adsorption and charge neutralization or enmeshment (Alcantara, 2010; Pavanelli, 2001; Letterman et al., 1999). In biomass recovery with ferric chloride the mechanism of flocculation is of adsorption and charge neutralization, in which charges are reversed with flocculant overdose, as shown in Fig. 4, and the flocs formed are smaller than in the enmeshment process, however, the amount of flocculant used is lower. When a trivalent cation is used as flocculant, its ability to neutralize the charges is approximately 100 times greater than that of a monovalent cation and 10 times greater than that of a bivalent cation, thus, the amount of $\mathrm{FeCl}_{3}$ necessary is always less than the required for an electrolyte such as $\mathrm{FeSO}_{4}$ (Schulze-Hardy rule) to recover cells of cultures with the same biomass concentration.

Based on the characteristics of the sodium hydroxide, hydrolysis, adsorption, high solubility in water (about $27 \mathrm{~mol} \mathrm{~L}^{-1}$ ) and high alkalinity, the flocculation process with $\mathrm{NaOH}$ does not follow any of the three mechanisms described above. The 
separation of cells from the medium occurs due to changes in the isoelectric point of the solution (Chatelier law) by increasing $\mathrm{pH}$ of the solution, which allows for the destabilization of cells and their precipitation. Thus, when the $\mathrm{pH}$ of the cultivation medium is alkaline, the use of alkaline flocculants with high solubility is not viable for biomass recovery, because the amount of flocculant required to destabilize the cells is high.

\section{Effect of Salt Concentration in the Cultivation Medium on Flocculation Efficienc}

In order to verify the influence of salt concentration in the sample on the efficiency of flocculation, a defined amount of nutrients was added to the samples after cultivation in condition B but before flocculation, thus, each sample had the same biomass concentration, but different salinities. Sample 1 corresponds to the original sample obtained in cultivation condition $\mathrm{B}$, meanwhile, $5 \mathrm{~mL} \mathrm{~L}^{-1}$ and $9 \mathrm{~mL} \mathrm{~L}^{-1}$ of the nutrients solution of the modified Guillard " $\mathrm{f} / 2$ " medium were added to samples 2 and 3 , respectively. All samples were flocculated with $\mathrm{FeCl}_{3}$ at $0.2 \mathrm{mmol} \mathrm{L}^{-1}$. Results show that, as the concentration of salts (nutrients) in the cultivation medium increased from samples 1 to 3 , biomass recovery efficiency decreased, as shown in Fig. 5.

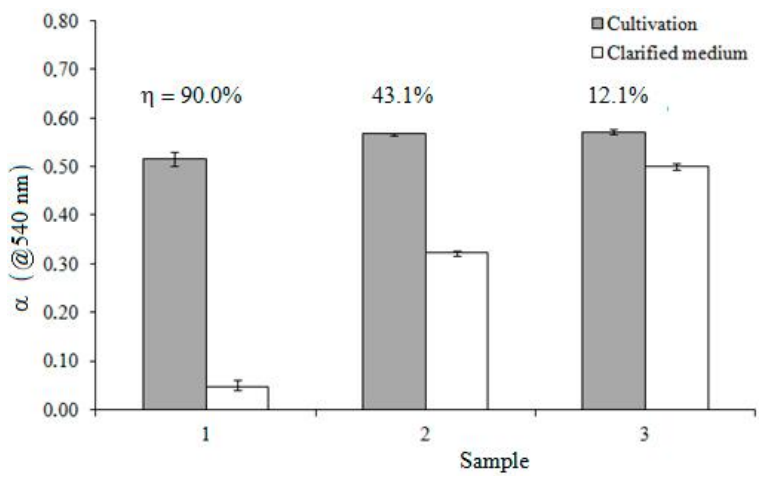

Figure 5. Variation of absorbance of samples 1 to 3 before and after flocculation with $0.2 \mathrm{mmol} \mathrm{L}^{-1}$ of

$\mathrm{FeCl}_{3}$. Biomass recovery efficiencies are also shown.

\section{Lipid Content of Microalgae A. obliquus Recovered by Flocculation and Centrifugation}

Lipid content of recovered biomass was analyzed in order to verify if the selected flocculants caused cell damage leading to loss of intracellular lipid. Lipid concentration in samples recovered with the optimum concentrations of flocculants were compared to lipid content in the sample recovered by centrifugation, which is assumed not to have affected the lipid concentration, as shown in Fig. 6. Flocculation with $\mathrm{FeCl}_{3}$ did not alter lipid content in biomass $(p>0.05)$. On the other hand, there was a reduction in cellular lipid content of $19.70 \%$ for flocculation with $\mathrm{NaOH}$, indicating that the use of $\mathrm{NaOH}$ as flocculant may rupture cell membrane, leading to loss of lipid content in microalga $A$. obliquus biomass. Therefore, the use of $\mathrm{NaOH}$ as flocculant would not be viable for biomass recovery of microalga A. obliquus in processes designed for lipid production.

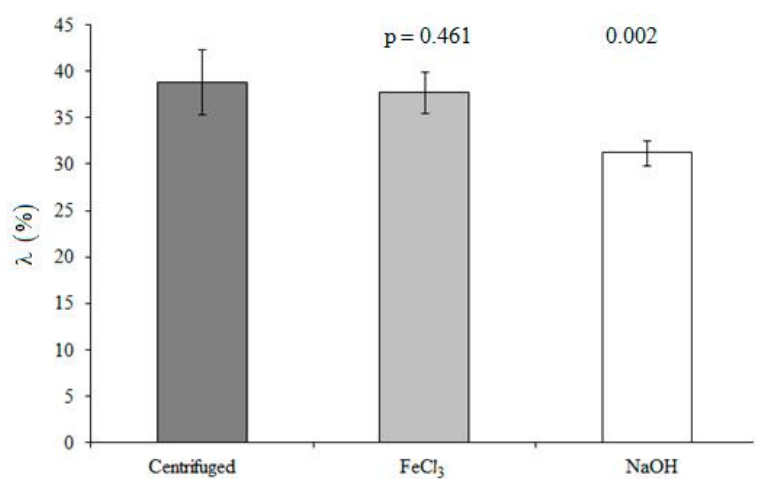

Figure 6 . Lipid content $(\lambda)$ in biomass recovered by centrifugation and flocculation with $0.2 \mathrm{mmol} \mathrm{L}^{-1}$ of $\mathrm{FeCl}_{3}$, and with $8 \mathrm{mmol} \mathrm{L}^{-1} \mathrm{NaOH}$.

\section{DISCUSSION}

During a flocculation process, as a flocculant is dispersed in the sample, its ions bind to the extracellular charges of the cells as well as to other ions in solution, thus, the amount of flocculant required for biomass recovery increases with medium salinity and biomass concentration. Consequently, it is difficult to compare the concentrations of flocculant used and to reproduce the flocculation efficiency with the same concentration of flocculant with different samples, even with the same biomass concentration, since cultivation conditions may alter both final biomass concentration and salinity.

Sodium hydroxide is described as an option for flocculation of marine microalgae biomass that does not damage cells (Soares, 2010; Horiuchi et al., 2003; $\mathrm{Wu}$ et al., 2012). However, marine microalgae are subject to different environmental conditions than freshwater microalgae, such as higher salinity and pressure, so that their cell membrane is more resistant. Thus, $\mathrm{pH}$ variations that do not damage cells of marine microalgae may disrupt cells of microalga A. obliquus.

Flocculation with ferric chloride, on the other hand, does not affect cellular integrity and presents a higher biomass recovery efficiency. In addition, it does not generate a significant change in $\mathrm{pH}$ and ferric chloride is also a component of the microalgae culture medium, thus, if the clarified medium were to be reused as a new growth media (Kim et al., 2011; Rodolfi et al., 2003) it would not be necessary to correct the $\mathrm{pH}$ and the increment in salinity at each recycling step would be small, unlike what would occur if the cultivation had been flocculated with $\mathrm{NaOH}$. 


\section{CONCLUSIONS}

Flocculation is an economically viable process for the recovery of biomass for the production of low valued products from microalgal oil, such as biodiesel. In comparison with centrifugation, the energy consumption in a flocculation process is considerably lower. The evaluation of flocculation followed by sedimentation presented in this study showed that this method is efficient as a process for biomass recovery from microalga $A$. obliquus, resulting in a higher removal efficiency than that of centrifugation. Since biomass recovered with ferric chloride contains the same concentration of lipids than biomass recovered with centrifugation, it is reasonable to state that ferric chloride has potential to recover biomass of microalga $A$. obliquus without any loss of cellular lipid content.

\section{ACKNOWLEDGEMENTS}

This work was supported by the National Council for Scientific and Technological Development, $\mathrm{CNPq}$, Brazil under Grants 407198/2013-0, 403560/2013-6, and 407204/2013-0; and Araucaria Foundation, Parana, Brazil under Grant 39428-316/2014.

\section{REFERENCES}

Alcantara, F. J. V., 2010, Estudo Comparativo de Dois Leitos Filtrantes com Porosidades Distintas em Sistemas de Dupla Filtração para Tratamento de Água, Master Thesis, Universidade Federal de Alagoas, Maceió, AL. (in Portuguese)

Beltrão, N. E. M., and Oliveira, M. I. P., 2010, Oleaginosas e seus Óleos: vantagens e Desvantagens para Produção de Biodiesel, Documentos, Vol. 201, EMBRAPA Algodão, Campina Grande. (in Portuguese)

Chen, L., Wang, C., Wang, W., and Wei, J., 2013, Optimal Conditions of Different Flocculation Methods for Harvesting Scenedesmus sp. Cultivated in an Open-Pond System, Bioresource Technology, Vol. 133, pp. 9-15.

Chisti, Y., 2007, Biodiesel from Microalgae, Biotechnology Advances, Vol. 25, pp. 294-306.

González-Fernández, C., Sialve, B., Bernet, N., and Steyer, J. P., 2012, Impact of Microalgae Characteristics on their Conversion to Biofuel. Part I: Focus on Cultivation and Biofuel Production, Biofuels, Bioproducts and Biorefining, Vol. 6, pp. 105-113.

Grima, E. M., Belarbi, E. H., Fernández, F. G. A., Medina, A. R., and Chisti, Y., 2003, Recovery of Microalgal Biomass and Metabolites: process Options and Economics, Biotechnology Advances, Vol. 20, pp. 491-515.

Horiuchi, J., Ohba, I., Tada, K., Kobayashi, M., Kanno, T., and Kishimoto, M., 2003, Effective Cell
Harvesting of the Halotolerant Microalga Dunaliella tertiolecta with $\mathrm{pH}$ Control, Journal of Bioscience and Bioengineering, Vol. 95, pp. 412-415.

Huang, G. H., Chen, F., Wei, D., Zhang, X. W., and Chen, G., Biodiesel Production by Microalgal Biotechnology, Applied Energy, 2010, Vol. 87, pp. 38-46.

Hundt, K., and Reddy, B. V., 2011, Algal Biodiesel Production from Power Plant Exhaust and its Potential to Replace Petrodiesel and Reduce Greenhouse Gas Emissions, International Journal of Low-Carbon Technologies, Vol. 6, pp. 294-298.

Kim, D. G., La, H. J., Ahn, C. Y., Park, Y. H., and Oh, H. M., 2011, Harvest of Scenedesmus sp. with Bioflocculant and Reuse of Culture Medium for Subsequent High-Density Cultures, Bioresource Technology, Vol. 120, pp. 3163-3168.

Lee, A. K., Lewis, D. M., and Ashman, P. J., 2009, Microbial Flocculation, a Potentially Low-Cost Harvesting Technique for Marine Microalgae for the Production of Biodiesel, Journal of Applied Phycology, Vol. 21, pp. 559-567.

Letterman, R. D., Amirtharajah, A., and O'Melia, C. R., 1999, Water Quality and Treatment, ed. R. D. Letterman, 5th Edition, McGraw-Hill Inc, New York.

Lourenço, S. O., 2006, Cultivo de Microalgas Marinhas, RiMa, São Carlos. (in Portuguese)

Mallick, N., Mandal, S., Singh, A. K., Bishai, M., and Dash, A., 2012, Green Microalga Chlorella vulgaris as a Potential Feedstock for Biodiesel, Journal of Chemical Technology and Biotechnology, Vol. 87, pp. 137-145

Meng, X., Yang, J., Xu, X., Zhang, L., Nie, Q., and Xian, M., 2009, Biodiesel Production from Oleaginous Microorganisms, Renewable Energy, Vol. 34, pp. 1-5.

Pavanelli, G., 2001, Eficiência de Diferentes Tipos de Coagulantes na Coagulação, Floculação e Sedimentação de Água com Cor ou Turbidez Elevada, Master Thesis, Universidade de São Paulo, São Paulo, SP. (in Portuguese)

Pienkos, P. T., and Darzins, A., 2009, The Promise and Challenges of Microalgal-Derived Biofuels, Biofuels, Bioproducts and Biorefining, Vol. 3, pp. 431-440.

Rodolfi, L., Zittelli, G. C., Barsanti, L., Rosati, G., and Tredici, M. R., 2003, Growth Medium Recycling in Nannochloropsis sp. Mass Cultivation, Biomolecular Engineering, Vol. 20, pp. 243-248.

Rodríguez, J. A., Palau, L. C., and López, M. O. A., 2007, Extracción y Cuantificación de Lípidos, in: Métodos y Herramientas Analíticas en la Evaluación de la Biomasa Microalgal, ed. B. O. A. Vega, D. Voltolina, CIBNOR, La Paz, ch. 6, pp. 47-57. (in Spanish)

Schlesinger, A., Eisenstadt, D., Bar-Gil, A., Carmely, H., Einbinder, S., and Gressel, J., 2012, Inexpensive Non-Toxic Flocculation of Microalgae Contradicts Theories; Overcoming a Major Hurdle to 
Bulk Algal Production, Biotechnology Advances, Vol. 30, pp. 1023-1030.

Soares, D., 2010, Avaliação do Crescimento Celular e da Produtividade de Lipídeos de Microalgas Marinhas em Diferentes Regimes de Cultivo, Master Thesis, UFPR, Curitiba, PR. (in Portuguese).

Uduman, N., Danquah, Y. Qi, M. K., Forde, G. M., and Hoadley, A., 2010, Dewatering of Microalgal Cultures: a Major Bottleneck to Algae-Based Fuels, Journal of Renewable and Sustainable Energy, Vol. 2, pp. 012701.

Wu, Z., Zhu, Y., Huang, W., Zhang, C., Li, T., Zhang, Y., and Li, A., 2012, Evaluation of Flocculation Induced by $\mathrm{pH}$ Increase for Harvesting Microalgae and Reuse of Flocculated Medium, Bioresource Technology, Vol. 110, pp. 496-502.

Wyatt, N. B., Gloe, L. M., Brady, P. V., Hewson, J. C., Grillet, A. M., Hankins, M. G., and Pohl, P. I., 2012, Critical Conditions for Ferric Chloride-Induced Flocculation of Freshwater Algae, Biotechnology and Bioengineering, Vol. 109, pp. 493-501. 